Mini Review

\title{
Research Progress of Magnetic Field Techniques for Electrodeposition of Coating
}

\author{
Qiong Long ${ }^{1, *}$, Yunbo Zhong, ${ }^{2, *}$, Jianming $W u^{1}$ \\ ${ }^{1}$ Guizhou Key Laboratory for preparation of light metal materials, Guizhou Institute of Technology \\ Guiyang 550003, China \\ ${ }^{2}$ State Key Laboratory of Advanced Special Steel, Shanghai Key Laboratory of Advanced \\ Ferrometallurgy, School of Materials Science and Engineering, Shanghai University, Shanghai 200444, \\ China \\ *E-mail: qiong12030@163.com (Qiong Long); yunboz@staff.shu.edu.cn (Yunbo Zhong)
}

doi: $10.20964 / 2020.08 .40$

Received: 1 April 2020 / Accepted: 19 May 2020 / Published: 10 July 2020

\begin{abstract}
Recent advances in electrodeposition techniques under magnetic fields are introduced. The mechanism of magnetic fields to electrochemical deposition technology, including mass transfer, coating structure modification, electrochemical reaction and crystal orientation are reviewed. Current research results show that MHD effect induced by the Lorenz force and the magnetization effect are the main factors. The research situation of single metal layer, alloy layer, composite coatings and high entropy alloy layer under magnetic fields is summarized. Finally, and the problems existing in current research of magnetic electrochemistry are pointed out, and the development prospect of controllable magnetoelectrodeposition is also proposed.
\end{abstract}

Keywords: Electrodeposition; Magnetic field; MHD effect; Magnetization effect; Prospect

\section{FULL TEXT}

(C) 2020 The Authors. Published by ESG (www.electrochemsci.org). This article is an open access article distributed under the terms and conditions of the Creative Commons Attribution license (http://creativecommons.org/licenses/by/4.0/). 